\title{
Can Innovation Platforms (IPs) Improve Rural Women Participation in Maize Value Chain? Evidence from the Eastern DR Congo
}

\author{
Paulin Njingulula, Paul K. Matungulu, Kenneth F. Masuki, Marc Schut, Chris C. Okafor \\ Bennjamin M.Wimba
}

\begin{abstract}
This study explored the potential of the Innovation Platform approach, in improving the participation of rural female farmers in Maize value chain. It intends to identify the peculiarities, in terms of challenges and opportunities related to its application to the rural women realities. The study collected data from 120 small-scale maize producers in South Kivu province of the Democratic Republic of Congo (DRC) from 2015 to 2017, using individual interview and focus group discussion (FGD) for data confirmation. Data was analyzed using the Average Effect of Treatment of treated (ATT) and the propensity matching score to assess the effect of IP approach on rural women, who were randomly selected to participate in an innovation platform composed solely of women $(100 \%)$ against those participating in a mixed innovation platform, made of $70 \%$ of men. The results show that the Innovation platform approach allowed women to address their basic challenges and improve their participation in the maize value chain. Average individual income from participation to the Innovation Platform increased from $\$ 100$ to $\$ 300$ per cropping season and the average earning of a women in a platform made of women solely was \$552.6 higher than that of women participating in mixed platform \$432.4. We hypothesized that the main benefits from the female IP would be increased maize yields. However, the analysis shows that although yield increased, the main effect was due to improved market access provided by the "IP." The implementation of the innovation platform process encountered several challenges, in particular: building a consensus when the interests of the groups in place have proven to be divergent, the barrier of social consideration (social stereotype), inability of smallholder's farmers to learn quickly and fully play expected role, the traditional culture of learning, visioning the process. Despite these challenges, IPs offered small-scale maize producers many technical, organizational and material opportunities, including income generation, access to inputs and to lucrative markets, acquisition of diversified knowledge and skills, ability to work in a commercial environment, benefiting from the services of experts, accessing new sources of financing, they could not benefit otherwise. These findings imply that to be effective for rural women, an innovation platform should include individuals with no wide social disparity and diversify the sources of income, including livestock and others off farm activities.
\end{abstract}

Published on May 21, 2020.

Paulin Njingulula is a Socio-economist, and value chain Specialist with INERA - DRC (pnjingulula@gmail.com)

Paul K. Matungulu is a Project Manager with International Institute of Tropical Agriculture (IITA) - DRC. (P.Matungulu@cgiar.org)

Kenneth F. Masuki is with Association for Land use, Environmental care Research and Technology transfer (ALERT), Tanzania. (kennymasuki@gmail.com)
Keywords - Innovation platform, participation, rural women, value chain.

\section{INTRODUCTION}

Women play a major role as agricultural producers in many regions of the world. However, their access to resources and opportunities to enable them to move from subsistence to business-oriented agriculture is much lower than that of men [1], [2]. Women-owned farming businesses face many more constraints (e.g. including lower mobility, less access to training, less access to market information, less access to productive resources, family and ethnic negative background) and receive fewer services and less support than those owned by men [3], [4], [5], [6]. These disadvantages reduce women's effectiveness as actors in value chains and reduce overall market profitability [7]. Studies carried out in Burkina Faso, Kenya and Tanzania have shown that providing women producers and entrepreneurs with the same inputs and education as men could result in an increase in their output and incomes by an estimated 10-20 percent [8].

Over recent years, the Sub-Sahara African Challenge Program (SSA-CP) attempted to revolutionize innovation and diffusion processes in rural Africa using an "innovation system" perspective, integrating and building on knowledge and preferences from stakeholders across the production and distribution chain. Innovation systems approaches build on the premise that the capacity of stakeholder to innovate is determined by the organizations, their resources, and the policy frameworks within which they operate. It also promotes the idea that innovation itself is a result of the interactions between numerous public and private actors and organizations within the system, and that approaches to enhance innovation systems should be participatory in nature, and seek to engage not only researchers, but also representatives from appropriate government bodies as well as producers, intermediaries, customers, and financial organizations. A popular approach to bring together these stakeholders is through so-called innovation platforms that are aimed at enabling bottom-up searches for solutions to

Marc Schut is a Senior Scientist with International Institute of Tropical Agriculture (IITA) and Wageningen University (m.schut@cgiar.org)

Chris Okafor is an Action Area Coordinator, International Institute of Tropical Agriculture (IITA), East and Central Africa, DRC. (C.Okafor@cgiar.org). 
local bottlenecks [9]. Innovation platforms are acknowledged as social structures that can internalize transaction costs, facilitate efficient information flow, and reduce both farmers' risk aversion toward new technologies and income shocks through collective risk management [10]. In this context, the established innovation platform serves to develop market linkages while increasing the power of negotiation of rural producers vis-à-vis to urban buyers as a main consumption niche. Participants are envisioned to be a learning group rather than a passive absorber of information, capable of contributing to problem solving and practical solutions to agribusiness.

In South-Kivu, Eastern Democratic Republic of Congo (DRC), an initiative to implement the innovation platform approach has been undertaken to facilitate rural producers in accessing institutional service support, improved technologies, better markets to improve their production and commercialization [11]. In the pilot implementation phase of this project in Rutsuru and Masisi, women, representing 20\% of participants, were not major actors in the process. Although this pilot phase produced encouraging results, such as increase in income of beneficiaries from $\$ 120$ to $\$ 400$ per season [12], these mainly male-led IPs did not benefit women smallholder farmers. The unequal socio-cultural and economic status of women limited their participation in the male-led IPs. It is against this background that this research was designed, with the aim to ascertain whether the organization of innovation platforms, mainly for female actors (PIF) would better solve the problems of effective participation of female producers in the maize value chain and if would positively solve the current limitations that women face in terms of marketing their crop produce.

The main objective of this research is to evaluate whether IPs that specifically focusing on women's participation lead to better outcomes for women. The study also seeks to identify the peculiarities, in terms of challenges, lessons and recommendations for the application of the IPs approach in the specific context of rural women. In addition, it intends to improve common understanding of the rural reality for women that can serve as a starting point to identify possible pathways to foster improvements in the IP's approach.

Three main research questions are addressed in this paper: (1) What is the contribution of IP's approach to reducing poverty through research for development project? (2) What is the mean effect of the project for a particular type of individual having a particular prerequisite such as level of education among those who participate to the program? (3) Which particular challenges and opportunities do IPs with high relative women participation present?

\section{Methodology}

\section{A. Study area}

This study was conducted in South Kivu Province of the DRC. The region is characterized by high population density coupled with high levels of unemployment and poverty. More than $60 \%$ of the population is classified as poor and the proportion of poor women is higher than that of men [13], [14]. South Kivu has both low and high altitude agroecological regions from as low as $700 \mathrm{~m}$ to above $2000 \mathrm{~m}$ and agriculture is the dominant sector of the economy in the region accounting for over $65 \%$ of the GDP. The majority of the farmers are small-scale operators, with $86 \%$ cultivating less than 1 ha while the average size of a domestic farm ranges between 0.6 and 0.9 ha.

The experiment of the IP approach was conducted under the "Projet de Redynamisation de la recherche orientée sur le développement agricole (R4D) en République Démocratique du Congo (PRIA)" funded by the government of RDC, from 2014 to 2017. The aim of the project was to promote agricultural innovation in rural areas, with a particular focus on developing the agricultural value chain. The implementation stage was organized as an experiment with selection of IP's treatment into the sites. The two sites selected were Miti and Kamanyola. Miti is in the hills above Lake Kivu $(1583 \mathrm{~m})$ and is near the provincial capital of Bukavu. Kamanyola is on the Ruzizi Plains next to Lake Tanganyika (891-973 $\mathrm{m}$ ) and is between Bujumbura, the capital of Burundi, and the modest Congolese town of Uvira [15]. The two sites receive rainfall between $1200-1800 \mathrm{~mm}$ per year. This region has two growing seasons, season A from September to January and the small season B from midFebruary to June.

\section{B. Innovation Platform establishment}

At each site, 2 innovation platforms (IPs) were established. The number of the platform members depended on the institution and services available at each site. The members were composed of different types of individuals, groups or organizations who agreed to be engaged in the IP. These included farmers, representatives of research institutions that develop new technologies, public services and NGOs involved in the dissemination of new technologies, private inputs providers and merchants, and a few key consumers in the region. The IPs had an average membership between 45 to 50 people. Each IP elected a steering committee. Farmers received improved maize seeds, inputs and training on agricultural practices. Meetings were held at the beginning of each crop season. During meetings, IP members had to decide in a participatory manner on the types of training to have, inputs types and source and markets to be targeted. Input and credit agreements and related trainings were provided by service providers (within the platforms). Other monitoring and evaluation meetings were scheduled throughout and at the end of a crop season. Demo and seed multiplication plots were established by each IP, and harvested seeds were distributed among IP members to establish their own individual maize production plot. A field monitoring committee collected data and ensured that members applied the needed recommendations. At the harvest, the committee aggregated the quantities produced, sold them to the buyers and gave each IP member his proportional share of money after withdrawing the shares due to the suppliers of inputs and credits. During the evaluation of the IPs process, individual interviews followed by the focus group discussion (FGD) were conducted to gather view of participants and nonparticipants on the process. This made it possible to understand and explain certain phenomena that were difficult to explain from the quantitative and qualitative collected data during the implementation process. 


\begin{tabular}{l|l|c|c|c}
\multicolumn{4}{|c}{ TABLE I: SAMPLE DISTRIBUTION } \\
\hline Site & Gender & \multicolumn{3}{|c}{ Overall } \\
\cline { 3 - 5 } & & Mix & PFF & Overall \\
\hline Miti & Female & 10 & 30 & 40 \\
& Male & 20 & 0 & 20 \\
& Sub total & $\mathbf{3 0}$ & $\mathbf{3 0}$ & $\mathbf{6 0}$ \\
\hline Kamanyola & Female & 10 & 30 & 40 \\
& Male & 20 & 0 & 20 \\
& Sub total & $\mathbf{3 0}$ & $\mathbf{3 0}$ & $\mathbf{6 0}$ \\
\hline Grand Total & & $\mathbf{6 0}$ & $\mathbf{6 0}$ & $\mathbf{1 2 0}$ \\
\hline
\end{tabular}

The sample for this study was made of 120 farmers, maize producers, divided into four innovation platforms. Two platforms are mixed (MIX), composed by 40 men and 20 women. The other two are made up of only female actors (PFF).

\section{Analytical framework}

The study seeks to measure the effect of treatment on treated or the contribution of this program to increase women income (the effect of household participation to the study on poverty reduction / household income). The simple way of doing so is to consider the difference, let say the mean income between women who participated and those who did not participate. However, taking this difference as a causal relationship between participation and non-participation raises several problems including the selectivity bias [16], [17]. In case where this difference may be positive, it does not tell us that there is a causal relationship and whether or not participation leads to income increase. It may happen that a part of the income difference between participants and nonparticipants, existed even before project starts. It is against this background geared towards solving the selectivity bias problem that experimental and non-experimental approaches were developed.

In this research we suppose that participation of women to the program would lead to heterogeneous results, as we do not expect all women to obtain the same results when participating in the IP program. To check this, the Average Treatment Effect on the treated (ATT) and the propensity matching score [18], [19] were used as it's sometimes done in the literature of impact assessment [20], [21], [22]. The propensity matching score approach allowed us to match individuals who participated in the platform with those who did not participate but having the same characteristics. The Average Treatment Effect on the treated allowed us to estimate the effect of participation in IPs.

The propensity scores in this study were calculated using the platform adhesion equation, which is a Logit regression model using platform adhesion as the binary variable $(1=$ Adhesion and $0=$ Non-adhesion). Characteristics that may affect participation were carefully examined to better assess propensity scores. In this study, we used the Epanechnikov kernel matching as in [23], established at a rate of $\sqrt{N}$ with its asymptotic normality. This allowed us to associate similar characteristics of a women adhering to the platform to that of one who did not adhere. The (households observable) characteristics associated included age, farm size, income, marital status, area and education.

\section{Specification of the model}

The equation to estimate the model in this work is given by:

$$
\begin{array}{r}
\mathrm{Li}_{\mathrm{i}}=\left(\frac{P_{i}}{1-P_{i}}\right) \text { Individual performance }=\beta 0+\beta 1(\text { Age })+\beta 2 \\
(\text { Educ })+\beta 3(\text { site })+\beta 4(\text { farm size })+\beta 5(\mathrm{Qtyprod})+\beta 6 \\
(\text { Hincom })+\beta 7+\beta 8(\text { marstatus })+\varepsilon
\end{array}
$$

Where $d=1$ if the individual participates in innovation platform, $d=0$ if the individual does not participate and explanatory variables have the characteristics specified in

\begin{tabular}{|c|c|c|c|c|}
\hline Variable & Acronym & Nature & $\begin{array}{l}\text { Expecte } \\
\text { d sign }\end{array}$ & Modality \\
\hline \multirow{2}{*}{$\begin{array}{l}\text { Platform } \\
\text { membershi } \\
\text { p }\left(L_{i}\right)\end{array}$} & Adeplat & Qualitative & & $\begin{array}{l}1= \\
\text { Membership }\end{array}$ \\
\hline & & & & $\begin{array}{l}0 \\
\text { Membership }\end{array}$ \\
\hline $\begin{array}{l}\text { Age of head } \\
\text { of } \\
\text { household }\end{array}$ & Age & $\begin{array}{l}\text { Quantitativ } \\
\mathrm{e}\end{array}$ & Negative & Year of birth \\
\hline Group & $\begin{array}{l}\text { Kamanyol } \\
\text { a }\end{array}$ & Qualitative & Negative & $\begin{array}{l}\text { On } 2 \\
\text { Groupings }\end{array}$ \\
\hline $\begin{array}{l}\text { Level of } \\
\text { education }\end{array}$ & AnneEduc & $\begin{array}{l}\text { Quantitativ } \\
\mathrm{e}\end{array}$ & Positive & $\begin{array}{ll}\text { Number } & \text { of } \\
\text { years } & \text { of } \\
\text { study } & \end{array}$ \\
\hline Farm size & Fsiz & Qualitative & Positive & $\begin{array}{l}\text { Cultivated } \\
\text { Area }\end{array}$ \\
\hline $\begin{array}{l}\text { Amount } \\
\text { produced }\end{array}$ & Qtyprod & $\begin{array}{l}\text { Quantitativ } \\
\mathrm{e}\end{array}$ & Positive & $\begin{array}{l}\text { Total } \\
\text { quantity } \\
\text { produced }\end{array}$ \\
\hline $\begin{array}{l}\text { Household } \\
\text { income }\end{array}$ & Hincom & $\begin{array}{l}\text { Quantitativ } \\
\mathrm{e}\end{array}$ & Positive & $\begin{array}{l}\text { Total } \\
\text { Household } \\
\text { Income }\end{array}$ \\
\hline Married & marstatus & Qualitative & $\begin{array}{l}\text { Not } \\
\text { predicted }\end{array}$ & $\begin{array}{l}1=\text { Single; } 0 \\
=\text { If not the } \\
\text { case }\end{array}$ \\
\hline Widow & marstatus & Qualitative & $\begin{array}{l}\text { Not } \\
\text { predicted }\end{array}$ & $\begin{array}{l}1 \\
\text { Marry; } 0=\text { If } \\
\text { not the case }\end{array}$ \\
\hline
\end{tabular}
Table-1.

TABLE 1: LIST OF VARIABLES

\section{E. Descriptive statistics}

This choice was guided essentially by the nature of our data that doesn't permit to view the situation of individuals sampled before participation and after participation in the platform. But, if it were the case the double difference would be appropriated. However, the endogenous problem occurred given that some factors which affect profitability was not captured, such as the soil fertility, rain and others specific agro-ecological aspects related to maize production. Then, using a least square ordinary to estimate the effect of participation on profitability there was an underestimate of the causal effect due to residues.

To avoid this problem, a regression with instrumentals variables can be used. But the main difficult is that in many cases we don't have adequate tools to support or instruct farmer's characteristics. Given that the goal of impact assessment studies was to prove counterfactual - which means that how would be the profitability of individuals who had participated if they couldn't participate and vice versa. But in reality, it is difficult to prove that because for the units in the sample, only one of the potential outcomes, Yi (0) and $\mathrm{Yi}(1)$, is observed and the other is unobserved or missing.

Thus, if there is assurance that the status of participation in the platform is randomly determined, the impact can be evaluated by doing a difference between the average profit or 
income of those who participate and those who didn't participate, which is an experimental approach. In noexperimental approach, the difference in different method, the regression with instrumental variables and the propensity matching score are commonly methods, which are used. In the light of the above, the propensity matching score will be used in this study.

In the case of this study the variable $\mathrm{Y}$ with an expected value $\mathrm{E}(\mathrm{Y})$ in a population of $\mathrm{n}$ household is divided into two groups, on one hand, those who participate in platform made only with women (PFF) (which represent treatment group) and on the other hand those who didn't participate (which represent control group). Consequently, we have a binary variable, which take 1 as value for those who participate in the platform and take 0 as value for those who didn't participate.

As formalized in [24], the model of assessment impact assumes two values of target variable for every individual; the value of the interest variable $\mathrm{Yi}$ become $\mathrm{Y}_{\mathrm{i}}^{\mathrm{T}}$ for individuals in the treatment group and $\mathrm{Y}_{\mathrm{i}}{ }^{\mathrm{C}}$ for those who are in the control group. So, the impact of participation in a platform on profitability of individual $i$ will be the difference between those two values of interest variable as is follow.

$$
\mathrm{G}_{\mathrm{i}}=\mathrm{y}_{\mathrm{i}}^{\mathrm{T}}-\mathrm{y}_{\mathrm{i}}^{\mathrm{C}}
$$

Where $G_{i}$ is the impact or causal effect of participation in a platform on profitability.

However, this can only be true if there is no problem of selection bias. That is, if the two populations (beneficiaries and non-beneficiaries) are homogeneous except that one is treated and the other one not treated

Because it is difficult to calculate that causal effect for every individual, the literature suggests to use the average treatment effect $\Delta^{\mathrm{ATE}}$ which is the sum of the average impact $\Delta^{\mathrm{TT}}$ of the treatment group and the average impact of the control group $\Delta^{\mathrm{TU}}$.

$$
\Delta^{\mathrm{ATE}}=\Delta^{\mathrm{TT}}+\Delta^{\mathrm{TU}}
$$

The estimation of $\Delta^{\mathrm{TT}}$ and $\Delta^{\mathrm{TU}}$ is doing within respectively samples of treatment group and control group. Is also interesting to know the conditional average impact given some characteristics of households. Let $\mathrm{X}$ be the vector of those characteristics. The conditional average impact of the treatment group will become:

$$
\Delta^{\mathrm{TT}}(\mathrm{X})=\mathrm{E}(\mathrm{G} \mid \mathrm{X}, \mathrm{T}=1)
$$

and the conditional average impact of the control group will become

$$
\Delta^{\mathrm{TU}}(\mathrm{X})=\mathrm{E}(\mathrm{G} \mid \mathrm{X}, \mathrm{T}=0)
$$

Thus, the sum of those conational average impacts gives us the conditional average treatment effect:

$$
\Delta^{\mathrm{ATE}}(\mathrm{X})=\mathrm{E}(\mathrm{G} \mid \mathrm{X}, \mathrm{T}=1)+\mathrm{E}(\mathrm{G} \mid \mathrm{X}, \mathrm{T}=0)
$$

In practice, the popular method assumes that those three averages impact are equals and we have:

$$
\begin{aligned}
& \mathrm{G}_{\mathrm{i}}=\Delta^{\mathrm{ATE}}=\Delta^{\mathrm{TT}}=\Delta^{\mathrm{TU}} \text { for all household } \\
& \text { Thus, } \mathrm{Y}_{\mathrm{i}}=\Delta^{\mathrm{ATE}} T_{i}+\mathrm{Xi} \beta_{\mathrm{i}}^{\mathrm{c}}+\mu_{\mathrm{i}}^{\mathrm{C}}
\end{aligned}
$$

Where $Y_{\mathrm{i}}$ is the income earned by an household $I$ is the welfare component (Poverty status, per capita expenditures, income, productivity etc.)

$\Delta^{\mathrm{ATE}} T_{i}$ is the average treatment effect.

$\mathrm{Xi} \beta_{\mathrm{i}}^{\mathrm{c}}$ is the slope of the vectors

$\mu_{\mathrm{i}}^{\mathrm{C}}=$ Error term

To avoid some constrains, the errors terms of those two groups are assumed equals, so we have $\mu_{i}^{\mathrm{C}}=\mu_{\mathrm{i}}^{\mathrm{T}}$. Even if this procedure is important in the estimating of average effect of participation in platform on profitability (income), other many hypotheses are necessaries to have parameters without bias. To be conclusive, let us suppose $\mathrm{D}(\mathrm{X})$ be the difference between the average of interest variable of those two groups. Thus, we have:

$$
\mathrm{D}(\mathrm{x})=\Delta^{\mathrm{TT}}(\mathrm{X})=\Delta^{\mathrm{TT}}(\mathrm{X})+B^{T T}(X)
$$

And

$$
B^{T T}(X) \equiv \mathrm{E}\left(Y^{T} \mid \mathrm{X}, \mathrm{T}=1\right)+\mathrm{E}\left(Y^{C} \mid \mathrm{X}, \mathrm{T}=0\right)
$$

by using $\mathrm{D}(\mathrm{x})$ in the estimation of $\Delta^{\mathrm{TT}}$

\section{RESULTS AND DISCUSSION}

\section{A. The individual participation of members to the platform activities over the time.}

We used the meeting attendance, labor provision, payment of fees and other work organized by the group as indices to evaluate the individual participation of members to the platform activities. The intensity of individuals participation changed over the time and shows the ability of the women maize producers to engage in networks, cooperate and make use of social relationships for collective action, the so-called 'collective efficacy' [25]. We did this to understand if there was a difference in relative motivation index of members (ability to get and stay motivated) between men and women. Graphs 1 and 2 show how the participation of members in the platform activities evolved over the time. 


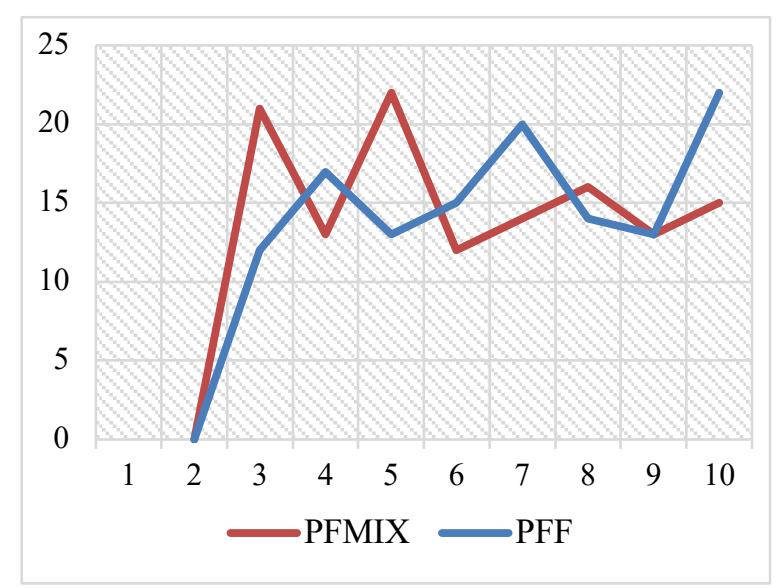

Fig. 1. Members' participation to platform in Miti.

Fig. 1 and Fig. 2 show how evolved the participation of men and women over the time in the platform activities. It shows difference between the two components. Whether in Miti or Kamanyola, women start timidly and when they understand the process, they increase their participation. Which is different from the observed trend for men

\section{B. Seed production in the multiplication plot}

The quantity of seed production depends, on the area planted, the type of seed used, the climatic conditions and the cropping system applied. In the study, the platforms of the same sites, Miti or Kamanyola had the same plot size, used the same quantity and type of seed, received the same training and therefore were expected to produce the same yields,

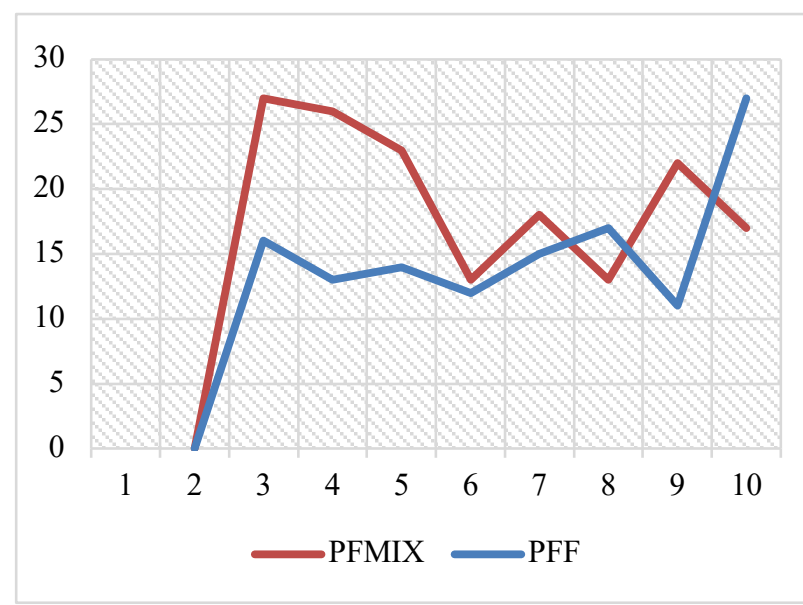

Fig. 1. Members' participation to platform in Kamanyola.

ceteris paribus. However, the results obtained in the field show a great disparity between the sites and between the platforms. Although we observed a difference between the sites, which is explained by the fact that arable land fertility is more noticeable in the plain of Ruzizi (Kamanyola) than in the highlands of Kabare (Miti), we observed a large difference between the quantities produced by different IPs. At Miti the women's platform registered a higher production compared to the mixed one, i.e. $1194 \mathrm{~kg}$ and $1045 \mathrm{~kg}$ respectively. This same trend is observed in Kamanyola where the women produced $1560 \mathrm{~kg}$ compared to the mixed platform, $1356 \mathrm{~kg}$. This shows that, at certain extent, women have ability, once organized, to produce as men do, or even more.

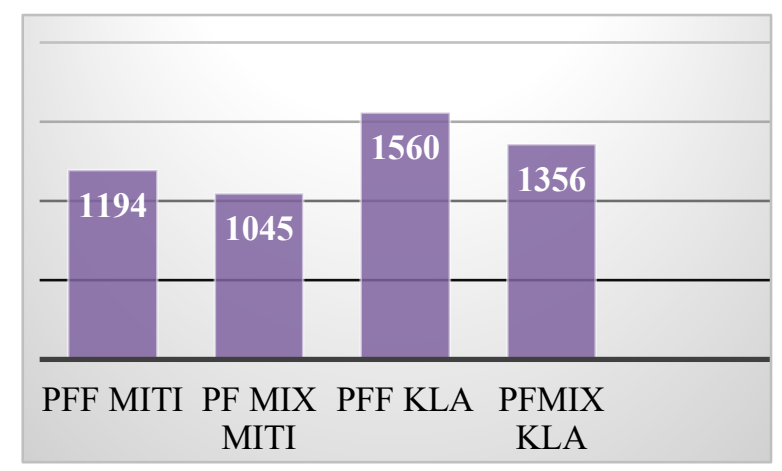

Fig 2. Quantity of seeds produced during 2015A cropping season 


\begin{tabular}{|c|c|c|c|}
\hline & Treated $(60)$ & Over all (120) & \\
\hline \multicolumn{4}{|c|}{ Gender member (\%) } \\
\hline Male & 0 & 45 & 46.66 \\
\hline Female & 60 & 15 & 73.34 \\
\hline \multicolumn{4}{|l|}{ Marital statute (\%) } \\
\hline Bachelor & 14.53 & 13.998 & 20.004 \\
\hline Married & 39.77 & 34.002 & 82.668 \\
\hline Widow & 11.67 & 12 & 17.328 \\
\hline \multicolumn{4}{|l|}{ Type of group (\%) } \\
\hline Female group & 30 & 30 & 60.00 \\
\hline Mix group & 30 & 30 & 60.00 \\
\hline \multicolumn{4}{|l|}{ Age $(\%)$} \\
\hline Under 25 years & - & - & - \\
\hline $25-35$ years & 10.998 & 4.002 & 15.000 \\
\hline $45-55$ years & 22.001 & 13.998 & 35.999 \\
\hline Over 55 years & 10.998 & 19.998 & 30.996 \\
\hline \multicolumn{4}{|c|}{ Level of Education (\%) } \\
\hline No formal education & - & - & - \\
\hline Primary & 10.002 & 12 & 21.336 \\
\hline Secondary & 42 & 42 & 84 \\
\hline Graduated & 7.998 & 6 & 14.664 \\
\hline Bachelor & - & - & - \\
\hline
\end{tabular}

Table 3 presents results of quantitative variables of individual sampling. As we can see, in the treatment group all individuals sampled are females. But in the control group most individuals are male approximately seventy percent from thirty percent of female. According to marital status of maize sellers sampling there are more married $(66.2 \%$ and $56,67 \%)$ in the two groups under analysis. According to the age of sellers sampling, we saw that in the treatment group a high percent of individual was between forty-five and fiftyfive years old but in the control group individuals were between thirty-five and forty-five years old. Most of individuals sampled have a secondary level of education $(70 \%)$ in the treatment group and the control group.

TABLE 3: INCOME, AREA AND MAIZE QUANTITY PRODUCE

\begin{tabular}{|c|c|c|c|c|c|c|c|c|c|}
\hline & \multicolumn{9}{|l|}{ Sites } \\
\hline & \multicolumn{3}{|l|}{ Miti } & \multicolumn{3}{|c|}{ Kamanyola } & \multicolumn{3}{|l|}{ Overall } \\
\hline & Treated & Control & T-test & Treated & Control & T-test & Treated & Control & T-test \\
\hline Income (mean \$) & 343.7 & 234.6 & $(-2.683)^{* *}$ & 764.5 & 628.2 & $(-4.8) * * *$ & 552.6 & 432.4 & $(-4.028) * * *$ \\
\hline Area (Mean Ha) & 0.58 & 0.56 & $(-0.238)$ & 0.90 & 0.94 & $(0.325)$ & 0.74 & 0.75 & $(0.164)$ \\
\hline $\begin{array}{l}\text { Education (Mean year) } \\
\text { Qty Harvest (Mean Kg) } \\
\text { N }\end{array}$ & $\begin{array}{l}10.9 \\
1193.5 \\
30\end{array}$ & $\begin{array}{l}10.8 \\
1045 \\
15\end{array}$ & $\begin{array}{l}(-0.108) \\
(-2.175)^{*}\end{array}$ & $\begin{array}{l}11 \\
1560 \\
30\end{array}$ & $\begin{array}{l}11.4 \\
1356 \\
15\end{array}$ & $\begin{array}{l}(0.48) \\
(-2.063)^{*}\end{array}$ & $\begin{array}{l}10.9 \\
2138.6 \\
60\end{array}$ & $\begin{array}{l}11.1 \\
1438.2 \\
60\end{array}$ & $\begin{array}{l}(0.243) \\
(-2.848)^{* * *}\end{array}$ \\
\hline
\end{tabular}

Table 4 above shows the average income earned by the two groups. It reveals that the IPs played an important intermediary role in stimulating and influencing innovation processes such as shifting from subsistence to commercial Maize production, whereby women gained access to urban market and improved their income. Ordinary women sell maize in isolation to street traders at a price of $\$ 6$ for a $50 \mathrm{~kg}$ bag. The maize sold by the platform was delivered directly to the urban market at a price of about $\$ 18$ in Bukavu per $50 \mathrm{~kg}$ bag, which means an increase of 300 percent of income. The average earning of a woman in a platform made of women solely was $\$ 552.6$ higher than that of women participating in mixed platform $\$ 432.4$. This difference between the two groups is statistically significant at 0.05 level. The average area cultivated in hectare in treatment group is not much different to the average area cultivated in the control group respectively 0.74 and 0.75 . The variable years of education shows that sellers in the treatment group and control group had very close (10.95 and 11.1) years of education respectively.

To perform the matching score propensity, we firstly estimated the logit model to determine the variables, which affect the probability for being member of platform. The following points showed results of this estimation. Secondly the results of matching estimation are provided.

As we can see in the following table, only two variables influence significantly the probability of participation in a platform. One of them - income - affects the probability positively. To be married and areas influence the probability of being member positively, but not significantly different. The analysis of the pseudo $\mathrm{R}^{2}$ shows that this model explains fifty-tree percent of change in participation in the platform. 
TABLE 4: IDENTIFICATION OF DRIVERS OF MEMBERSHIP IN PLATFORM (LOGISTIC ESTIMATIONS)

\begin{tabular}{|c|c|c|c|c|c|c|}
\hline \multirow{2}{*}{ Variables } & \multicolumn{2}{|l|}{ Miti } & \multicolumn{2}{|l|}{ Kamanyola } & \multicolumn{2}{|l|}{ Overall } \\
\hline & Coef. & $\mathrm{Z}$ & Coef. & $\mathrm{Z}$ & Coef. & Z \\
\hline Areas & $.2898354(.4561951)$ & 0.64 & $2.039489(1.384868)$ & 1.47 & $.1182092(.0944589)$ & 1.25 \\
\hline Age & $.0432198(.0219811)$ & $1.97 * *$ & $-.027024(.1125398)$ & -1.13 & $.0484577(.0177748)$ & 1.34 \\
\hline Anne_educ & $.1283667(.0911293)$ & $1.41 * *$ & $-.9798047(.8655125)$ & $1.65^{*}$ & $.0896171(.0666476)$ & $2.22 * *$ \\
\hline Income & $.0032018(.0043487)$ & 0.74 & $.0048299(.0029337)$ & -0.24 & $.0013539(.0006091)$ & $2.73 * * *$ \\
\hline Married & $-.5288555(.4675013)$ & -1.13 & $-1.244409(1.316999)$ & -0.94 & $-.4620508(.3679712)$ & -1.26 \\
\hline Number of obs & & 60 & & 60 & & 120 \\
\hline $\mathrm{LR} \mathrm{Chi}^{2}(6)$ & & 5.75 & & 46.06 & & 29.3 \\
\hline Prob $>\mathrm{Chi}^{2}$ & & 0.65 & & 0.000 & & 0.000 \\
\hline Pseudo $\mathrm{R}^{2}$ & & 0.1 & & 0.804 & & 0.25 \\
\hline
\end{tabular}

Note: figures in parenthesis are standard deviations

The results show that the signs of all coefficients were in the expected direction, but not all were statistically significant. The probability of earning more income increases significantly with farmers who have high level of education, income of the farmer in the previous season and those that have large farm sizes. However, the income earned decreases significantly with farmers' age. This can be explained by the fact that the ability to apply new technology on a specific farm clearly is influenced by the farmers' age. Young farmers seem to be more active than old farmers as far as trying new things in rural poor farming context is concerned. This means increasing age hypothetically reduces the probability of applying new technologies. This might be because of factors inherent in the aging process or the lowered likelihood of payoff from a shortened planning horizon over which accepted benefits can accrue [26].

TABLE 5: AVERAGE TREATMENT BY KERNEL COMMON MATCHING ON INCOME (\$) (ANY TYPE OF PLATFORM)

\begin{tabular}{|c|c|c|c|c|c|c|}
\hline Site & Sample & Treated & Controls & Difference & S.E. & T-stat \\
\hline \multirow[t]{2}{*}{ Miti } & Unmatched & 343.75 & 194.653333 & 149.096667 & 55.5695707 & 2.68 \\
\hline & ATT & 227.273684 & 226.100419 & 1.1732651 & 43.2255684 & 0.03 \\
\hline \multirow[t]{2}{*}{ Kamanyola } & Unmatched & 764.554387 & 628.289765 & 136.48667 & 303.270644 & 4.82 \\
\hline & ATT & 338.426476 & 334.058349 & 4..0379649 & 28.1766068 & 0.57 \\
\hline \multirow[t]{2}{*}{ Overall } & Unmatched & 1108.30438 & 822.386432 & 285.917948 & 199.9029 & 4.03 \\
\hline & ATT & 282.85008 & 240.079384 & 42.7706159 & 71.4021752 & 0.6 \\
\hline
\end{tabular}

The second line in table above (ATT, Average Treatment Effect on the treated) corresponds to the comparison of the productivity of households treated (membership of platform) and that of untreated households (no member) and having the same characteristics. This impact is estimated higher in favour of households treated. Combined with the earlier results that last season's income and education are significant, we can conclude that educated and higher income woman have a larger tendency to participate.

\section{Challenges}

1) During evaluation of the process it came out that women who did not have enough intellectual capacity did not achieve good records when compared to those having high education level. Responding to the question" did you feel confident working with other platform members? Some of them (16\%) said it was difficult to feel confident in a group where there was a great social disparity between participants. Social homogeneity seems to be an important factor in the collective action for rural women. It appeared that social disparity among the members, far from being a motivation to stimulate rural women participation, was found to be a source of frustration for those who did not perform well. This may explain the inefficiency of women in a mixed group which implies that platforms to be effective for rural women should include individuals with no wide social disparity.

2) About $34 \%$ of smallholder farmers complained that given the small size of farmland, they generally apply the intercropping for family subsistence. However, the increase in family income induced by the participation in the value chain (IP participation), moving from subsistence cropping (intercropping) to the marketoriented cropping (the monoculture) certainly was not enough to produce, in the short term, significant improvements in the diet of the family as advocated by the IP approach. The fact that they have devoted the full extent of land available to the production of Maize, has led to the reduction of the quantities of self-produced food, which has not necessarily been rewarded by the positive effects of the generated income which was assigned to the pressing needs at the moment, such as school fees and medical 
services/bills. This implies that, to be useful for rural women, an innovation platform should diversify the sources of income, including livestock and others off farm activities.

3) The actors participating in this IPs process came from different horizons with different background. At the beginning of the process they showed divergent objectives and ambitions, linked to conflicting or competitive interests. The fragility of the link between different categories of members arose when the priorities had to be defined. People of different category tended to coalesce and form one block that wove one against the other. For example, private inputs providers find it too long for them to supply farmers with inputs on the credit basis and be paid at the harvest time, four months later. For farmers that was the only suitable solution. These openly expressed positions likely reinforced the status quo in IPs consensus, in which farmers had limited voice and power in decision making processes and led to lack of engagement and 'buy-in' from farmers. In these conditions it was difficult to work together trusting each other, to cooperate effectively or to share useful information with each other. The big challenge then was to build trust and consensus among the members, and lead the divergence towards common ground, a common understanding of the issues, a mutual coordination of activities to deal in a concerted way with the identified problems and thus take advantage of the opportunities that offered each part. This confirms the findings of the study in [27], who found that innovation platforms alone may not lead to system-wide change and large-scale impact if they are not systematically facilitated to improve governance, or if they are not embedded in the existing institutional environment

4) Farmers in the platform seemed not equipped with the technical, organizational and management skills needed to play their role in the platform effectively. They often showed frustration, and other actors tended to take advantage of this situation by imposing solutions that favored them. On other hand, the desire to push the actors to reach a consensus did not lead to "solutions" that suited all the actors involved, especially those who did not have enough power. This led to a hiring of a well experienced external facilitator who helped actors to reach shared understanding, organize themselves better and set a capacity building program to enhance members skill and ability to work as partners.

\section{CONCLUSION AND RECOMMENDATIONS}

This paper sought to address three key research questions. The first question was related to "What is the mean effect (contribution) of project on women poverty reduction or what is the contribution of IP's approach to reducing poverty through research for development project?

Our experience showed that the IP approach has the potential to improving women's participation as an actress in the commercial value chains. Through the platform, small-scale female producers had effective access to improved inputs such as seeds and fertilizer, received training and practical skills in maize production. This led to women's access to the lucrative market and increased income. We found that group membership leads to a significant increase in members' income, but only for those women who market their produce collectively. This underlines that it is not only the group membership that matters, but also the degree of participation in certain group activities. For how long they will still be having access to the inputs and markets beyond the project, is one of areas that need future investigation.

The second question was related to: "What are the factors that determine women participation in IPs? What is the mean effect of the project for a particular type of individual having a particular prerequisite such as level of education among those who participate to the program?" the study showed that women who did not have enough intellectual capacity found it difficult to perform in a group where there is a great social disparity between participants. Social homogeneity seems to be an important factor in the collective action for rural women. It appeared that social disparity among the members was seen to a source of frustration for women with low education level. This implies that for platforms to be effective for rural women, they should include individuals with less social disparity. Future research needs to focus on this case, to find out how to improve participation of women in mixed IPs, because it is socially difficult to find a situation where women operate sustainably without men.

The third question was related to: "What are the peculiarities in terms of challenges and opportunities of IP approach implementation for rural poor women? The implementation of the innovation platform process encountered several challenges, in particular: building a consensus when the interests of the groups in place have proven to be divergent, the barrier for social consideration (social stereotype), inability of smallholder farmers to learn quickly and fully play expected role, the traditional culture of learning, visioning the process. Despite these challenges, IPs offered small-scale maize producers many technical, organizational and material opportunities, including income generation, access to inputs and to lucrative markets, acquisition of diversified knowledge and skills, ability to work in a commercial environment, benefiting from the services of experts, accessing new sources of financing, they could not benefit otherwise.

\section{ACKNOWLEDGMENTS}

This research was made possible by PRIA funded by RDC government. Paulin Njingulula, would like to extend sincere gratitude to the rural households and enumerators who participated in this research.

\section{REFERENCES}

[1] C. Man-Kwun, "Improving Opportunities for Women in Smallholder-based Supply Chains: Business Case and Practical Guidance for International Food Companies," Prepared for the Bill \& Melinda Gates Foundation. 2010.

[2] ičp:C. B. Barrett, "Smallholder market participation: concepts and evidence from eastern and southern Africa," Elsevier (Ed.). Science Direct, Food Policy 33:99-317. 2008.

[3] E. Bardasi, C. M. Blackden, and J. C. Guzman, "Gender, Entrepreneurship, and Competitiveness in Africa," World Bank. 2007. 
[4] A. Ellis, C. Manuel, and M. Blackden, "Gender and Economic Growth in Uganda: The Power of Women, Directions in Development," World Bank. 2006.

[5] WORLD BANK [a], "Global Monitoring Report 2007: Millennium Development Goals: Confronting the Challenges of Gender Equality and Fragile States," Washington, DC: World Bank. 2007.

[6] WORLD BANK [b], "Gender and Economic Growth in Tanzania," Washington, DC: Directions in Development, 2007

[7] Lastarria-Cornhiel, "Impact of privatization on gender and property rights Africa," Elsevier, Volume 25, Issue 8, Pages 1317-1333. 1997.

[8] K. S. Oueraogo, C. Y. Kabore-Zoungrana, I. Ledin, (2008), "Important characteristics of some browse species in an agrosilvopastoral system in West Africa," Available at https://www.feedipedia.org/node/4552

[9] H. Pamuk, E. Bulte, A. A. Adekunle, "Do decentralized innovation systems promote agricultural technology adoption? Experimental from Africa," Elsevier, Food Policy 44 (2014) 227-236. 2014.

[10] E. Bulte, G. Beekman, S. Di Falco, J. Hella, "Behavioral Responses and the Impact of New Agricultural Technologies: Evidence from a Double-blind Field Experiment in Tanzania", American Journal of Agricultural Economics, Pp 813-830:SE-P, 2017

[11] R. Hawkins, W. Heemskerk, R. Booth, J. Daane, A. Maatman and A. A. Adekunle. "Integrated Agricultural Research for Development (IAR4D), ” FARA, Accra, Ghana, pp. 2009.

[12] P. Njingulula, P. Wimba, M. Musakamba, K. F. Masuki, M. Katafiire, M. Ugen, E. Birachi, "Strengthening local seed systems within the bean value chain: Experience of agricultural platforms in the Democratic Republic of Congo," African Crop Science Journal, Volume, 22, pp 1003-1012, 2014.

[13] MINAGRI, "Monographie de la province du Sud - Kivu, Unité de Pilotage du Processus DSRP, Kinshasa/Gombe", 2014

[14] IITA, "The International Institute of Tropical Agriculture, IITAKalambo's annual report of crop-livestock integration project. Unpublished report. 2015

[15] S. Bacigale, L. Nabahungu, C. Okafor, G. Manyawu and A. Duncan, "Assessment of feed resources and potential feed options in the farming systems of Eastern DR Congo and Burundi", CLiP working paper no 3. 2018

[16] P. M. Dontsop-Nguezet, "Productivity Impact Differential of Improved Rice Technology Adoption Among Rice Farming Households in Nigeria," Journal of Crop Improvement 26(1): 1-21. 2012.

[17] A. Diagne, and A. Arouna, "Impact de la production de semence riz sur le rendement et le revenue des ménages agricoles: une étude de cas du Bénin," Paper presented at the $4^{\text {th }}$ International Conference of the African Association of Agricultural Economists, Hammamet, Tunisia, September 22-25. 2013.

[18] P R. Rosenbaum and D. B. Rubin, "The Central Role of the Propensity Score in Observational Studies for Causal Effects", Biometrika, Vol. 70, No. 1, pp. 41-55. April 1983.

[19] P. R. Rosenbaum and D. B. Rubin. Constructing a control group using multivariate matched sampling, in The American Statistician, vol 39, no 133.1985

[20] G. Esquivel and A. Huerta-Pineda, "The impact of migrant workers' remittances on living standards of families in Morocco: A propensity score matching approach," Transnational Press London. 2006

[21] M. Ravallion, "The contribution of demographic change to aggregate poverty measures for the developing world," Policy Research Working Paper Series 3580, The World Bank. 2005

[22] J. J. Heckman, R. LaLonde, and J. Smith, "The economics and econometrics for active labor market programs," Handbook of Labor Economics; Vol 3 (1) 1865-2097. 1999.

[23] J. J. Heckman, H. Ichimura, and P. Todd, "Characterizing selection Bias using experimental data," Econometrica, vol 66. no 5, pp. 1017-1098. 1998

[24] D. B. Rubin, "Estimating the causal effects of treatments in randomized and nonrandomized studies," The Journal of Educational Psychology, vol 66 (5), pp. 688-701. 1974

[25] J. Sampson, R. Jeffrey, D. Morenoff and Felton Earls, "Beyond Social Capital: Spatial Dynamics of Collective Efficacy for Children," American Sociological Review, vol. 64, No. 5 (Oct., 1999), pp. 633-660. 1999
[26] P. M. Dontsop-Nguezet "Impact of Nerica Rice on Rice farming households' welfare in Nigeria," Lambert Academic published, staarbruken, Deutchland. April, 2011

[27] M. Schut, (2018). "Innovation platforms in agricultural research for the development," Available at www.kit.nl.../2018/...5b1a850a93008_innovation_platforms_in_a gricultural_research_for_Development-1.pdf

\section{BIBLIOGRAPHY}

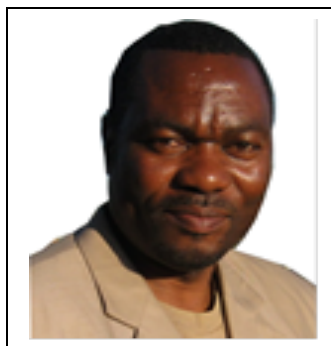

Paulin Ningulula is a Value Chain specialist at the International Institute of Tropical Agriculture, based in Bukavu, Republic Democratic of Congo.

He has a Master Degree in Agricultural Economics from the University of Pretoria(2011). He also holds an honours degree in Rural Development from the School of Rural Development, ISDR Bukavu (DR Congo).

Working with international and National agricultural research institutions (IITA, INERA, CIAT, PABRA, ECABREN, TSBF, ICRAF), Mr Njingulula has accumulated over ten years an invaluable experience on Agro value chain activities, Agricultural Research and Development, socioeconomic studies, bean and cassava market analysis, field survey, farmer training, group coordination and supervision and project planning and management. Data analysis and reporting, activities monitoring and evaluation. He has done some consultancy works with FAO, World Vision international, Hope Action and ICCO

Paul K. Mutungulu is a Project
Coordinator, from DR Congo.
He has a PhD in Agronomy (1992)
from the North Carolina University,
Raleigh, North Carolina, USA; an MSc
in Earth Sciences from Liege State
University, Belgium; and BSc
(Agriculture) at Ingenieur Agronome,
Faculte des Sciences Agronomique de




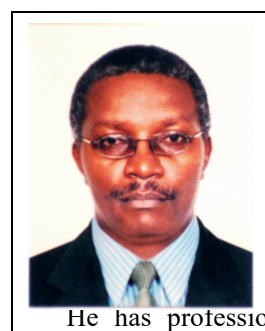

Kenneth F. Masuki is an Agricultural Scientist from Tanzania based in Arusha. He has a PhD in agricultural education and extension with focus in smallholder systems innovation from Sokoine University of Agriculture (2010), an MSc in Land and Water Engineering from University of Nairobi (2000) and BSc in agriculture with focus on soil science from Sokoine University of Agriculture (1991).

He has protessional experience in Agricultural Research and Development in national, regional and international organizations. He served as Principal Agricultural Research Officer in the Ministry of Agriculture, Tanzania, He worked as Knowledge Management Specialist with World Agroforestry Centre (ICRAF), he served as Programme Manager with ASARECA in Entebbe, Uganda, He also worked with CIMMYT as Project Country Coordinator for TAMASA Project in Tanzania. Currently, he is a member of a Tanzanian local NGO ALERT. He also serves as Independent R\&D Consultant. He has published a number of peer-reviewed journals, book chapters and a book.

Dr. Masuki is a member of some professional societies such as Soil Science Society of East Africa (SSSEA) and Global Water Partnership, Tanzania. He also has participated as a reviewer of journal of Experimental Agriculture.
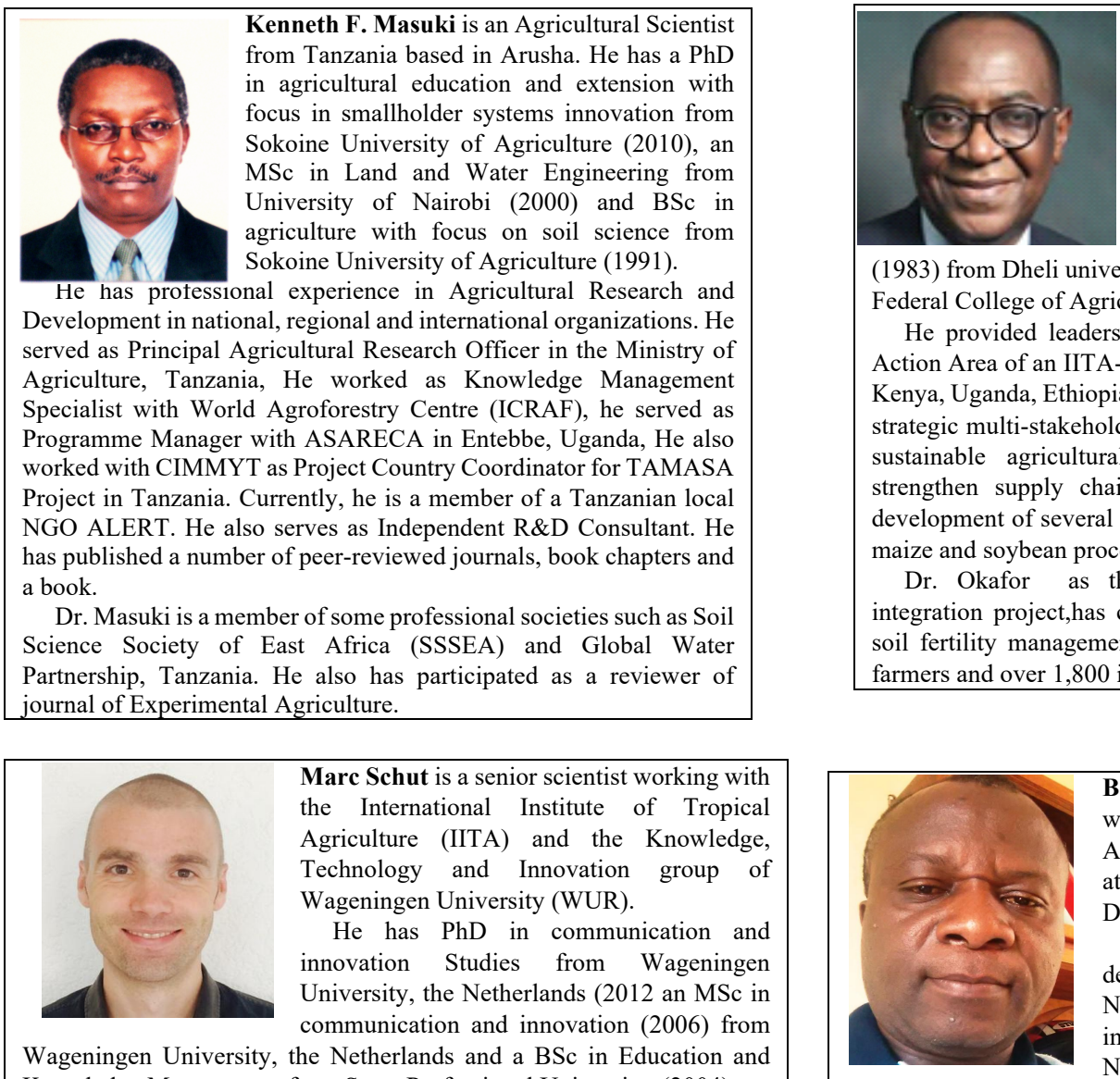

Christopher C. Okafor is the Head of IITA Kalambo Station \& Action Area Coordinator (ECA) w/ Humid tropics, Bukavu, South Kivu, DR Congo.

$\mathrm{He}$ has $\mathrm{PhD}$ in community development and program evaluation from the University of Ibanda (2000) a MSc in commerce and business administration (1983) from Dheli university and BBS in agriculture general from the Federal College of Agriculture/Ibanda

He provided leadership and operational oversight for the ECA Action Area of an IITA-led Humid tropics program covering parts of Kenya, Uganda, Ethiopia, Rwanda, Burundi, and the DRC for various strategic multi-stakeholder platforms (MSPs) established to generate sustainable agricultural solutions, improve credit access, and strengthen supply chain links across value chains. He led the development of several youth-led agri-enterprises including cassava, maize and soybean processing, aquaculture and poultry.

Dr. Okafor as the coordinator of IITA's crops-livestock integration project,has contributed to the deployment of integrated soil fertility management packages to over 800 direct smallholder farmers and over 1,800 indirect beneficiaries in the DRC. Wageningen University, the Netherlands and a BSc in Education and Knowledge Management from Stoas Professional University (2004)

$\mathrm{He}$ is based in Rwanda, from where he leads innovation and scaling under the CGIAR Research Program on Roots, Tubers and Bananas. He is also Principal Investigator of the CIALCA project that focuses on systems research and development of banana, cassava and potato production systems in Central Africa, and of a BMZ-funded project that explores the use of digital innovation and ICT for banana disease control and prevention. Skills and Expertise. He has published a number of scientific articles in the related subject in various journals and books implement adoption and impact assessment studies with CGIAR centers including CIAT, CIALCA .Wimba has as well as accumulated experience in Research for Development activities, including farmer; organization, training and linking to partners

He also has worked in data collection and data management at the INERA Mulungu in South Kivu 